\title{
Partial nephrectomy for T3aNOMO renal cell carcinoma: shall we step forward?
}

Ding Peng ${ }^{1}$, Zhi-song He ${ }^{1}$, Xue-song $\mathrm{Li}^{1}$, Qi Tang ${ }^{1}$, Lei Zhang ${ }^{1}$, Kai-wei Yang ${ }^{1}$, Xiao-teng Yu ${ }^{1}$, Cui-jian Zhang ${ }^{1}$, Li-qun Zhou ${ }^{1}$

${ }^{1}$ Department of Urology, Institute of Urology, Peking University First Hospital, Beijing, China

\section{ABSTRACT}

Objectives: To evaluate the prognosis of non-metastatic T3a renal cell carcinoma (RCC) with partial nephrectomy (PN).

Patients and Methods: We retrospectively evaluated 125 patients with non-metastatic T3a RCC. Patients undergoing PN and radical nephrectomy (RN) were strictly matched by clinic-pathologic characteristics. Log-rank test and Cox regression model were used for univariate and multivariate analysis.

Results: 18 pair patients were matched and the median follow-up was 35.5 (10-86) months. PN patients had a higher postoperative eGFR than RN patients $(\mathrm{P}=0.034)$. Cancer-specific survival (CSS) and recurrence-free survival (RFS) did not differ between two groups $(\mathrm{P}=0.305$ and $\mathrm{P}=0.524)$. On multivariate analysis, CSS decreased with positive surgical margin and anemia (both $\mathrm{P}<0.01$ ) and RFS decreased with Furhman grade, positive surgical margin, and anemia (all $\mathrm{P}<0.01$ ).

Conclusions: For patients with non-metastatic pT3a RCC, PN may be a possible option for similar oncology outcomes and better renal function.

\section{ARTICLE INFO}

\section{Keywords:}

Carcinoma, Renal Cell;

Nephrectomy; Patients

Int Braz J Urol. 2017; 43: 849-56

Submitted for publication:

November 05, 2016

Accepted after revision:

May 16, 2017

Published as Ahead of Print:

July 25,2017

\section{INTRODUCTION}

Radical nephrectomy (RN) used to be the standard therapeutic option for localized and locally advanced renal cell carcinoma (RCC) (1). In recent years, the oncology outcomes with partial nephrectomy (PN) were found not worse than those of RN (2). Moreover, PN may improve overall survival by preventing cardiovascular events caused by chronic kidney disease (CKD) for that the incidence of CKD was lower with PN than RN (3-5).

PN was recommended by the European Association of Urology and National Comprehensive Cancer Network guidelines as the preferred option for tumor type 1a-b (T1a-b) RCC $2(1,6)$. In recent years, several studies expanded the application further to T2 RCC patients (7). However, whether PN is a possible option for non-metastatic T3a RCC is unknown. Actually, some non-metastatic patients with pT3a RCC (perinephric and renal sinus fat invasion) have undergone PN for various reasons.

The aim of this study was to analyze the prognostic differences in T3a RCC patients who underwent PN or RN with a strictly case-matched design.

\section{PATIENTS AND METHODS}

We searched the renal cancer database in Peking University First Hospital for cases occurring from 2007 to 2012 and retrospectively 
identified 2651 RCC patients who underwent nephrectomy, including PN and RN. The study received institutional review board approval. According to the 2010 American Joint Committee on Cancer (AJCC) TNM staging, the patients included 125 with non-metastatic pathological T3a (pT3a) RCC; 18 underwent PN. Patients who underwent PN and RN were exactly matched by gender, age, tumor size, American Society of Anesthesiologists (ASA) score, pathological subtype, surgical margin status, tumor invasion status and Fuhrman grade (Table-1). When more than one RN patient with criteria identified was matched, we chose patients with a smaller difference in tumor size with PN patients.

Table 1 - Criteria for pair matching.

\begin{tabular}{lc}
\hline Criterion & Difference allowed \\
\hline Age & $<10$ years \\
Gender & Identical \\
Tumor size & $<3 \mathrm{~cm}$ \\
ASA score & Identical \\
Pathological subtype & Identical \\
Tumor invasion status & Identical \\
Surgical margin status & Identical \\
Fuhrman grade & Identical \\
\hline
\end{tabular}

Complete preoperative examinations included chest X-ray, abdominal ultrasonography, abdominal CT, laboratory examinations and other necessary exams for preoperative evaluation. Pathological specimens were assessed by at least two experienced pathologists to confirm the pathologic subtype, surgical margin status, tumor invasion status and lymph-node metastasis status. Histological subtype and Fuhrman grade were stratified according to the 2004 WHO classification system and 1997 WHO recommended standards, respectively. According to 2010 AJCC TNM staging system, T3a staging was diagnosed when the tumor grossly extended into the renal vein or its segmented (muscle- containing) branches or invaded the perirenal and/or renal sinus fat but not beyond Gerota's fascia.

Patients were followed up by the standard strategy for outpatients in our institution, every 3 months post-operatively for the first 2 years and every 6 months for the next 3 years. From the fifth year and thereafter, patients were followed up annually. The general follow-up included imaging examinations (chest X-ray, abdominal ultrasonography or CT) and laboratory examinations (blood, urine and biochemistry). The outcomes investigated during follow-up included cancer-specific survival (CSS) and recurrence-free survival (RFS). The period from the surgery date to the date of recurrence, death or last follow-up was calculated as the follow-up time.

Statistics analysis involved use of SPSS 22.0 (SPSS Inc., Chicago, IL). Student t test was used to compare continuous variables and chi-square test to compare categorical variables. Survival was estimated by Kaplan-Meier method and log-rank test was used for survival difference analysis and univariate analysis. Variables with significant differences on univariate analysis for all T3aNOMO patients were included in Cox multivariate regression analysis. All comparisons involved two-tailed tests and $\mathrm{P}<0.05$ was considered statistically significant.

\section{RESULTS}

A total of 18 patients with non-metastatic $\mathrm{pT}_{3 \mathrm{a}}$ renal cell carcinoma underwent $\mathrm{PN}$ in our institution. The reasons were solitary kidney $(n=3)$, renal insufficiency $(n=3)$ and preoperative diagnosis of clinical T1 or T2 (cT1 or cT2). From the matching variables, 18 patients who underwent $\mathrm{RN}$ were chosen as the control group. For the 36 patients, the median age was 68.5 years (range 36-85); 28 (77.8\%) were male and median followup was 35.5 months (10-86). The two groups did not differ in baseline characteristics $(\mathrm{P}>0.05)$ or some post-operative features such as blood loss $(\mathrm{P}=0.845)$, operative time $(\mathrm{P}=0.110)$, drainage-tube indwelling time $(\mathrm{P}=0.778)$ and post-operative stay $(\mathrm{P}=0.540)$. The preoperative eGFR in both groups is not significant different $(\mathrm{P}=0.357)$ and the postoperative eGFR in PN group is higher than RN 
Table 2 - Baseline characteristics and postoperative outcomes for patients with non-metastatic pT3a renal cell carcinoma (RCC) who underwent radical nephrectomy (RN) and partial nephrectomy (PN) ( $\mathrm{n=18}$ each).

\begin{tabular}{|c|c|c|c|}
\hline Variable & RN & PN & $P$ \\
\hline Age & $64.94 \pm 12.62$ & $60.89 \pm 13.99$ & 0.368 \\
\hline Male gender & 14 & 14 & Matched \\
\hline Histopathologic subtype & & & Matched \\
\hline $\operatorname{ccRCC}$ & 13 & 13 & \\
\hline non-ccRCC & 5 & 5 & \\
\hline Fuhrman grade & & & Matched \\
\hline 1 & 1 & 1 & \\
\hline 2 & 11 & 11 & \\
\hline 3 & 6 & 6 & \\
\hline ASA score & & & Matched \\
\hline 1 & 1 & 1 & \\
\hline 2 & 13 & 13 & \\
\hline 3 & 4 & 4 & \\
\hline Tumor size & $5.03 \pm 1.42$ & $5.27 \pm 1.50$ & 0.644 \\
\hline Tumor invasion & & & Matched \\
\hline Fat & 17 & 17 & \\
\hline Renal vein & 1 & 1 & \\
\hline Surgical margin & & & Matched \\
\hline Positive & 1 & 1 & \\
\hline Negative & 17 & 17 & \\
\hline Blood loss (mL) & $248.89 \pm 570.22$ & $287.22 \pm 598.03$ & 0.845 \\
\hline Operative time (min) & $157.44 \pm 45.04$ & $131.61 \pm 49.39$ & 0.110 \\
\hline Indwelling drainage tube time (day) & $4.94 \pm 4.14$ & $4.61 \pm 2.77$ & 0.778 \\
\hline Postoperative stay (days) & $7.61 \pm 2.50$ & $6.44 \pm 3.41$ & 0.250 \\
\hline Preoperative eGFR (mL/min/1.73m²) & $82.60 \pm 26.53$ & $73.99 \pm 27.97$ & 0.357 \\
\hline Postoperative eGFR (mL/min/1.73m²) & $52.35 \pm 17.21$ & $68.38 \pm 24.40$ & $0.034^{*}$ \\
\hline
\end{tabular}

Data are mean $\pm \mathrm{SD}$ or number. ${ }^{*} P<0.05$

ccRCC = clear cell renal cell carcinoma; $\mathbf{R N}=$ radical nephrectomy; $\mathbf{P N}=$ partial nephrectomy; $\mathbf{A S A}=$ American Society of Anesthesiologists

group $(\mathrm{P}=0.034)$ (Table-2).

At the end of follow-up, 4 (22.2\%) and 2 (11.1\%) patients in the PN and RN groups died due to the disease and $5(27.8 \%)$ and $4(22.2 \%)$ showed recurrence, respectively. The patients who died in the PN group were 1 with renal insufficiency, 3 up-graded after operation and the patients with recurrence in PN group were 1 for renal insufficiency, 1 with solitary kidney and 3 up-graded after operation. The estimated 5-year CSS for the PN and RN patients was $80.5 \%$ and $85.9 \%$, and the estimated 5-year RFS was 76\% and $80.8 \%$. CSS $(\mathrm{P}=0.305)$ and RFS $(\mathrm{P}=0.524) \mathrm{did}$ not differ between the two groups on log-rank testing (Figure-1).

Univariate analysis revealed that tumor invasion status, Fuhrman grade, positive surgical margin, hypoalbuminaemia and anemia were 
Figure 1 - Kaplan-Meier survival analysis of patients with non-metastatic $\mathrm{pT3a}$ renal cell carcinoma (RCC) who underwent radical nephrectomy (RN) and partial nephrectomy ( $P N)$. A) Cancer-specific survival $(P=0.305)$; $B)$ Recurrence-free survival $(\mathrm{P}=\mathbf{0 . 5 2 4 )}$.

A

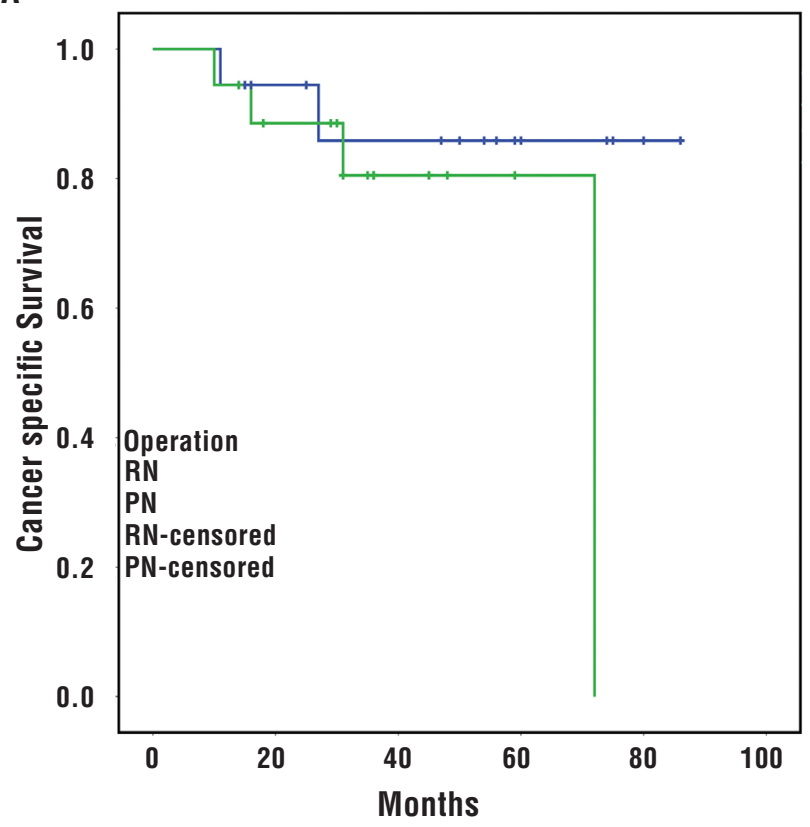

B

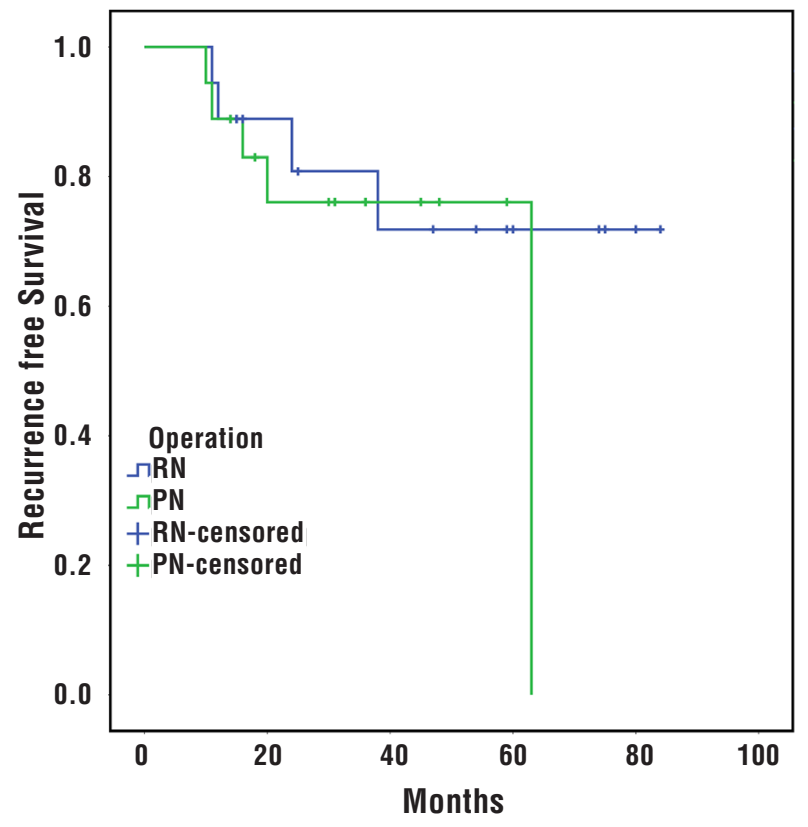

significantly associated with CSS and RFS for all T3aNOM0 patients $(\mathrm{n}=125)$ (Table-3). Surgical type (RN vs. PN) was not significantly associated with CSS and RFS. On Cox multivariate regression analysis, CSS was decreased with positive surgical margin $(\mathrm{P}=0.000)$ and anemia $(\mathrm{P}=0.003)$ and RFS was decreased with Fuhrman grade $(\mathrm{P}=0.001)$, positive surgical margin $(\mathrm{P}=0.003)$ and anemia $(\mathrm{P}=0.004)$ (Table-4).

\section{DISCUSSION}

From our institution's data on 125 patients with non-metastatic pT3a RCC, 18 patients with $\mathrm{PN}$ and 18 with RN were matched. We compared the outcomes of patients with localized RCC undergoing $\mathrm{PN}$ and other patients undergoing routine RN treatment to evaluate the outcomes and effectiveness of PN for non-metastatic T3a RCC. The postoperative eGFR in PN group is higher than RN group. CSS and RFS did not differ between the groups. In the multivariate analysis, positive surgical margin and anemia were independent risk factors for CSS and high Furhman grade, positive surgical margin, and anemia were risk factors for RSS.

A number of studies have shown no significant differences between $\mathrm{PN}$ and $\mathrm{RN}$ in survival with localized RCC $(2,8,9)$. Moreover, several studies suggested that PN could reduce the incidence of CKD and prevent the associated cardiovascular events and improve survival quality $(2,10)$. However, the therapeutic recommendation is still RN for T3aNOMO RCC (1, 6). Nevertheless, some T3a RCC patients undergo PN for various reasons such as solitary kidney and renal insufficiency. As well, a few patients were preoperatively diagnosed with cT1-2 cancer and treated with PN, which was pathologically upstaged to pT3a cancer.

In a study by Lee et al. (11), 43 (3.2\%) of 1367 patients with small RCC $(\leq 4 \mathrm{~cm})$ had pT3a lesions. Gorin et al. (12) retrospectively analyzed 1.096 cT1 patients after PN and found 41 (4.8\%) tumors upstaged to pT3a; the 2-year RFS with pT3a tumors was 91.8\%, which was lower than 
Table 3 - Univariate analysis of clinicopathological variables associated with cancer-specific survival (CSS) and recurrencefree survival (RFS) at 5 years for all $\mathrm{T}_{3 \mathrm{a}} \mathrm{N}_{0} \mathrm{M}_{0}$ patients ( $\left.\mathrm{n}=125\right)$.

\begin{tabular}{|c|c|c|c|c|c|c|c|}
\hline \multirow[t]{2}{*}{ Variable } & \multirow[t]{2}{*}{$\mathrm{n}$} & \multicolumn{3}{|c|}{ CSS } & \multicolumn{3}{|c|}{ RFS } \\
\hline & & CSS & $\chi^{2}$ & $P$ & RFS & $\chi^{2}$ & $\mathrm{P}$ \\
\hline Gender & & & 2.067 & 0.151 & & 2.840 & 0.092 \\
\hline Male & 87 & 65.4 & & & 53.1 & & \\
\hline Female & 38 & 74.2 & & & 69.7 & & \\
\hline Age, years & & & 0.736 & 0.391 & & 0.400 & 0.527 \\
\hline$<55$ & 49 & 69.6 & & & 59.1 & & \\
\hline$\geq 55$ & 76 & 67.5 & & & 57.7 & & \\
\hline BMI & & & 0.146 & 0.703 & & 0.230 & 0.632 \\
\hline$<25$ & 68 & 64.3 & & & 59.8 & & \\
\hline$\geq 25$ & 57 & 72.8 & & & 55.9 & & \\
\hline Tumor invasion & & & 9.772 & $0.002^{*}$ & & 4.231 & $0.040^{*}$ \\
\hline Fat & 89 & 78.6 & & & 64.6 & & \\
\hline Renal vein & 36 & 46.3 & & & 42.9 & & \\
\hline Histopathologic & & & 0.267 & 0.605 & & 0.801 & 0.371 \\
\hline subtype & & & & & & & \\
\hline $\operatorname{ccRCC}$ & 111 & 68.3 & & & 56.0 & & \\
\hline non-ccRCC & 14 & 68.8 & & & 77.4 & & \\
\hline Location & & & 1.206 & 0.272 & & 0.905 & 0.341 \\
\hline Left & 66 & 62.9 & & & 54.9 & & \\
\hline Right & 59 & 74.4 & & & 62.9 & & \\
\hline Tumor size, cm & & & 0.007 & 0.935 & & 0.310 & 0.578 \\
\hline$\leq 4$ & 9 & 83.3 & & & 58.3 & & \\
\hline$>4$ & 116 & 68.9 & & & 57.8 & & \\
\hline Fuhrman grade & & & 8.968 & $0.003^{*}$ & & 16.623 & $<0.001^{*}$ \\
\hline $1 \& 2$ & 60 & 85.7 & & & 79.6 & & \\
\hline $3 \& 4$ & 65 & 53.9 & & & 39.5 & & \\
\hline ASA score & & & 0.000 & 0.993 & & 0.834 & 0.361 \\
\hline $1 \& 2$ & 113 & 67.4 & & & 58.6 & & \\
\hline $3 \& 4$ & 12 & 76.2 & & & 60.0 & & \\
\hline Surgical type & & & 0.021 & 0.885 & & 0.101 & 0.751 \\
\hline RN & 107 & 67.3 & & & 56.6 & & \\
\hline PN & 18 & 80.5 & & & 76 & & \\
\hline Surgical margin & & & 46.172 & $<0.001^{\star}$ & & 16.169 & $<0.001^{*}$ \\
\hline Positive & 2 & 0 & & & 0 & & \\
\hline Negative & 123 & 69.1 & & & 59.2 & & \\
\hline Surgical approach & & & 0.061 & 0.805 & & 2.023 & 0.155 \\
\hline Open & 80 & 67.2 & & & 54.5 & & \\
\hline Laparoscopic & 45 & 74 & & & 67.8 & & \\
\hline Hypoalbuminaemia & & & 10.934 & $0.001^{*}$ & & 4.394 & $0.036^{*}$ \\
\hline No & 115 & 71.9 & & & 60.2 & & \\
\hline Yes & 10 & 20 & & & 28.6 & & \\
\hline Anemia & & & 22.03 & $<0.001^{*}$ & & 13.349 & $<0.001^{*}$ \\
\hline No & 102 & 75.6 & & & 63.7 & & \\
\hline Yes & 23 & 33 & & & 29.8 & & \\
\hline
\end{tabular}

${ }^{*} \mathrm{P}<0.05$

$\mathbf{B M I}=$ body mass index; $c c R C C=$ clear cell renal cell carcinoma; $\mathbf{R N}$ = radical nephrectomy; $\mathbf{P N}=$ partial nephrectomy; $\mathbf{A S A}$ = American Society of Anesthesiologists 
Table 4 - Multivariate analysis of clinicopathological variables for CSS and RFS for all $T_{3 a} N_{0} M_{0}$ patients $(n=125)$.

\begin{tabular}{|c|c|c|c|c|c|c|}
\hline \multirow[t]{2}{*}{ Variable } & \multicolumn{3}{|c|}{ cSS } & \multicolumn{3}{|c|}{ RFS } \\
\hline & $H R$ & $(95 \% \mathrm{Cl})$ & $P$ & $H R$ & $(95 \% \mathrm{Cl})$ & $P$ \\
\hline \multicolumn{7}{|l|}{ Tumor invasion } \\
\hline Fat & 1 & & & 1 & & \\
\hline Renal vein & 1.386 & $0.580-3.315$ & 0.463 & 1.201 & $0.593-2.432$ & 0.610 \\
\hline \multicolumn{7}{|l|}{ Fuhrman grade } \\
\hline $1 \& 2$ & 1 & & & 1 & & \\
\hline $3 \& 4$ & 1.865 & $0.701-4.961$ & 0.212 & 3.688 & $1.651-8.239$ & 0.001 \\
\hline \multicolumn{7}{|l|}{ Surgical margin } \\
\hline Positive & 41.318 & $\begin{array}{c}6.686- \\
255.331\end{array}$ & $<0.001^{*}$ & 10.861 & $2.231-52.873$ & 0.003 \\
\hline Negative & 1 & & & 1 & & \\
\hline \multicolumn{7}{|l|}{ Serum album, $g / L$} \\
\hline$\geq 35$ & 1 & & & 1 & & \\
\hline$<35$ & 1.678 & $0.580-4.855$ & 0.339 & 1.300 & $0.431-3.922$ & 0.642 \\
\hline \multicolumn{7}{|l|}{ Anemia } \\
\hline No & 1 & & & 1 & & \\
\hline Yes & 3.633 & $1.546-8.537$ & $0.003^{*}$ & 3.201 & $1.464-7.000$ & 0.004 \\
\hline
\end{tabular}

${ }^{*} \mathrm{P}<0.05$

$\mathbf{H R}=$ hazard ratio; $\mathbf{C l}=$ confidence interval

with pT1-2 tumors (99.2\%, P=0.003). Tumor upstaging was associated with a high R.E.N.A.L (radius, exophytic/endophytic, nearness to collecting system or sinus, anterior/posterior and location relative to polar lines) nephrometry score (hazard ratio $[\mathrm{HR}]$ 2.97, 95\% CI 1.20-7.35, $\mathrm{P}=0.02$ ), increased tumor diameter $(1.66,1.32-2.08, \mathrm{P}<0.001)$, and hilar location (2.83, 1.43-5.61, $\mathrm{P}=0.003)$. In another multi-institutional study, Nayak et al. (13) reported $134(9 \%)$ of 1.448 cT1 patients with upstaging to pT3a. The 3-year RFS with upstaging was $76 \%$ as compared with 93\% without upstaging $(\mathrm{P}<0.001)$. Disease recurrence, increasing age, Fuhrman grade and tumor size were independently associated with pathological upstaging. In our study, we found 11 of 125 (8.8\%) patients with non-metastatic pT3a RCC with cT1 cancer treated by PN.

Various risk factors associated with the oncology outcomes of non-metastatic RCC include age, gender, TNM, Fuhrman grade, tumor size, histopathologic subtype, ASA score and tumor invasion status $(14,15)$. Therefore, strict matching should be conducted to mitigate potential selection bias caused by these features. Lee et al. (11) found no significant differences between T1a and T3a patients in overall survival $(\mathrm{P}=0.521)$, CSS $(\mathrm{P}=0.651)$ and RFS $(\mathrm{P}=0.250)$. However, several variables such as age $(\mathrm{P}=0.015)$, tumor size $(\mathrm{P}<0.001)$, subtype $(\mathrm{P}=0.020)$, and Fuhrman grade $(\mathrm{P}=0.021)$ differed between the 2 cohorts. Jeldres et al. (16) matched pT3a RCC by age, gender, tumor size, Fuhrman grade and histopathologic subtype to create a cohort of PN patients $(n=30)$ and RN patients $(n=63)$ and demonstrated no significant difference between the groups in CSS $(\mathrm{P}=0.9)$. The authors also included all unmatched 72PN patients and 789RN patients in the multivariate analysis and found PN not associated with worse CSS as compared with $\mathrm{RN}$ ( $\mathrm{HR}=0.62$, $\mathrm{P}=0.11$ ). In our study, the matching criteria (gender, age, tumor size, ASA score, pathological subtype, surgical margin status, tumor invasion status and Fuhrman grade) were more stringent than that used by Jeldres et al., and we found no significant differences between the PN and RN groups in CSS 
$(\mathrm{P}=0.305)$ and RFS $(\mathrm{P}=0.524)$. As well, on univariate analysis of all T3aNOMO RCC patients, surgical type (PN or RN) was not associated with CSS or RFS.

Renal insufficiency has an independent and graded association with risk of death and cardiovascular events $(17,18)$. RCC patients have about a $25 \%$ rate of $\mathrm{CKD}$, which can lead to a series of metabolic disorders and cardiovascular events (19). PN was suggested to benefit renal function as compared with RN $(20,21)$. Sun et al. found a lower rate of postoperative renal events with PN versus RN (22). Yokoyama et al. (23) found RN as an independent risk factor for new-onset CKD. Jong Jin et al. (24) compared 45 T3a RCC patients who underwent PN and 298 patients who underwent $\mathrm{RN}$ and found that renal function, measured by postoperative creatinine $(\mathrm{Cr})$ and estimated glomerular filtration rate (eGFR), was better with PN than RN (Cr: 1.07 vs. $1.37 \mathrm{mg} / \mathrm{dL}, \mathrm{P}=0.001$; eGFR: 75.4 vs. $59.8 \mathrm{~mL} / \mathrm{min}$, $\mathrm{P}<0.001)$. However, RFS was lower for RN than PN patients $(\mathrm{P}<0.001)$. Because the mean tumor size was smaller for PN than RN patients $(\mathrm{P}<0.001)$, the authors also analyzed RFS for patients with tumor size $\leq 4 \mathrm{~cm}$ (30PN patients, 33RN patients) and found no significant difference $(\mathrm{P}=0.306)$. Similar to the results of patients with tumor size $\leq 4 \mathrm{~cm}$ in this previous study, we found similar CSS and RFS but higher postoperative eGFR for PN than RN patients $(\mathrm{P}=0.034)$ and this could imply that $\mathrm{PN}$ may protect renal function.

Positive surgical margin was previously found significantly associated with tumor recurrence, although the development of metastases and CSS were comparable with positive and negative surgical margins (25-27). Borghesi et al. (28) reported that the overall incidence of recurrence after negative surgical margins ranged from $0 \%$ to $7 \%$. In our study, 2 of 125 patients (1.6\%) with T3aNOMO RCC showed positive surgical margins and the variable was associated with CSS $(\mathrm{P}=0.000)$ and $\mathrm{RFS}(\mathrm{P}=0.000)$ on Cox multiple regression analysis. However, because of the low rate of positive surgical margins in singlecenter T3aNOMO RCC patients, the association with oncological outcomes demands larger cohort studies.

This study has several strengths. The experienced surgeons in a single center ensured that every patient received similar and standard treatment. Furthermore, the sequential and uniform follow-up provided high-quality data for analysis. Moreover, the characteristics of patients in the PN and $\mathrm{RN}$ groups were comparable with the strict case matching.

However, this study still presents several limitations. First, it was retrospective and cannot avoid the inevitable disadvantages of a retrospective study. Second, this is a small sample and single-center study, for a low ratio of T3a RCC patients undergoing PN and this cannot avoid the type 1 or 2 error. Third, the median follow-up time was short. Prospective, large-sample and multi-institutional studies are required to further test the use of $\mathrm{PN}$ and discover risk factors for non-metastatic T3a RCC patients.

In conclusion, this case-matched analysis demonstrates that for non-metastatic T3a RCC patients, PN may be is a possible option for similar oncology outcomes and better renal function.

\section{ACKNOWLEDGEMENTS}

Funding Support: This work was supported by the National Natural Science Foundation of China (Grant Number: 81372746 and 81672546).

Ding Peng and Zhi-song He contributed equally to this work

\section{CONFLICT OF INTEREST}

None declared.

\section{REFERENCES}

1. Ljungberg B, Bensalah K, Canfield S, Dabestani S, Hofmann $\mathrm{F}$, Hora $\mathrm{M}$, et al. EAU guidelines on renal cell carcinoma: 2014 update. Eur Urol. 2015;67:913-24.

2. Alanee S, Nutt M, Moore A, Holland B, Dynda D, Wilber A, et al. Partial nephrectomy for T2 renal masses: contemporary trends and oncologic efficacy. Int Urol Nephrol. 2015;47:94550.

3. Hansen J, Sun M, Bianchi M, Rink M, Tian Z, Hanna N, et al. Assessment of cancer control outcomes in patients with high-risk renal cell carcinoma treated with partial nephrectomy. Urology. 2012;80:347-53.

4. Roos FC, Steffens S, Junker K, Janssen M, Becker F, Wegener $G$, et al. Survival advantage of partial over radical nephrectomy in patients presenting with localized renal cell carcinoma. BMC Cancer. 2014;14:372. 
5. Tobert CM, Riedinger CB, Lane BR. Do we know (or just believe) that partial nephrectomy leads to better survival than radical nephrectomy for renal cancer? World J Urol. 2014;32:573-9.

6. Motzer RJ, Jonasch E, Agarwal N, Beard C, Bhayani S, Bolger GB, et al. Kidney cancer, version 3.2015. J Natl Compr Canc Netw. 2015;13:151-9.

7. Lane BR, Chen H, Morrow M, Anema JG, Kahnoski RJ. Increasing use of kidney sparing approaches for localized renal tumors in a community based health system: impact on renal functional outcomes. J Urol. 2011;186:1229-35.

8. Hadjipavlou M, Khan F, Fowler S, Joyce A, Keeley FX,et al. Partial vs radical nephrectomy for T1 renal tumours: an analysis from the British Association of Urological Surgeons Nephrectomy Audit. BJU Int. 2016;117:62-71. Erratum in: BJU Int. 2016; 117:E9.

9. Kopp RP, Mehrazin R, Palazzi KL, Liss MA, Jabaji R, Mirheydar HS, et al. Survival outcomes after radical and partial nephrectomy for clinical T2 renal tumours categorised by R.E.N.A.L. nephrometry score. BJU Int. 2014;114:708-18.

10. Lee HJ, Liss MA, Derweesh IH. Outcomes of partial nephrectomy for clinical T1b and T2 renal tumors. Curr Opin Urol. 2014;24:448-52.

11. Lee C, You D, Yoo S, Song C, Hong B, Hong JH, et al. Oncological outcomes of patients with incidental pathological T3a stage small renal cell carcinoma after partial nephrectomy. J Cancer Res Clin Oncol. 2016;142:1651-7.

12. Gorin MA, Ball MW, Pierorazio PM, Tanagho YS, Bhayani $\mathrm{SB}$, Kaouk JH, et al. Outcomes and predictors of clinical T1 to pathological T3a tumor up-staging after robotic partial nephrectomy: a multi-institutional analysis. J Urol. 2013;190:1907-11.

13. Nayak JG, Patel P, Saarela O, Liu Z, Kapoor A, Finelli A, et al. Pathological Upstaging of Clinical T1 to Pathological T3a Renal Cell Carcinoma: A Multi-institutional Analysis of Shortterm Outcomes. Urology. 2016;94:154-60.

14. Crispen PL, Boorjian SA, Lohse CM, Sebo TS, Cheville JC, Blute ML, et al. Outcomes following partial nephrectomy by tumor size. J Urol. 2008;180:1912-7.

15. Sun M, Shariat SF, Cheng C, Ficarra V, Murai M, Oudard S, et al. Prognostic factors and predictive models in renal cell carcinoma: a contemporary review. Eur Urol. 2011;60:644-61.

16. Jeldres C, Patard JJ, Capitanio U, Perrotte P, Suardi N, Crepel $\mathrm{M}$, et al. Partial versus radical nephrectomy in patients with adverse clinical or pathologic characteristics. Urology. 2009;73:1300-5.

17. Lee M, Jim HS, Fishman M, Zachariah B, Heysek R, Biagioli $M$, et al. Depressive symptomatology in men receiving androgen deprivation therapy for prostate cancer: a controlled comparison. Psychooncology. 2015;24:472-7.

18. McCullough PA, Li S, Jurkovitz CT, Stevens LA, Wang C, Collins AJ, et al. CKD and cardiovascular disease in screened high-risk volunteer and general populations: the Kidney Early Evaluation Program (KEEP) and National Health and Nutrition Examination Survey (NHANES) 1999-2004. Am J Kidney Dis. 2008;51(4 Suppl 2):S38-45.

19. Russo P. End stage and chronic kidney disease: associations with renal cancer. Front Oncol. 2012;2:28.

20. Krebs RK, Andreoni C, Ortiz V. Impact of radical and partial nephrectomy on renal function in patients with renal cancer. Urol Int. 2014;92:449-54.

21. Scosyrev E, Messing EM, Sylvester R, Campbell S, Van Poppel $\mathrm{H}$. Renal function after nephron-sparing surgery versus radical nephrectomy: results from EORTC randomized trial 30904. Eur Urol. 2014;65:372-7.

22. Sun M, Bianchi M, Hansen J, Trinh QD, Abdollah F, Tian Z, et al. Chronic kidney disease after nephrectomy in patients with small renal masses: a retrospective observational analysis. Eur Urol. 2012;62:696-703.

23. Yokoyama M, Fujii $Y$, limura $Y$, Saito K, Koga F, Masuda $\mathrm{H}$, et al. Longitudinal change in renal function after radical nephrectomy in Japanese patients with renal cortical tumors. J Urol. 2011;185:2066-71.

24. Oh JJ, Byun SS, Lee SE, Hong SK, Lee ES, Kim HH, et al. Partial nephrectomy versus radical nephrectomy for nonmetastatic pathological T3a renal cell carcinoma: a multiinstitutional comparative analysis. Int J Urol. 2014;21:352-7.

25. Ani I, Finelli A, Alibhai SM, Timilshina N, Fleshner N, Abouassaly R. Prevalence and impact on survival of positive surgical margins in partial nephrectomy for renal cell carcinoma: a population-based study. BJU Int. 2013;111:E300-5.

26. Antic T, Taxy JB. Partial nephrectomy for renal tumors: lack of correlation between margin status and local recurrence. Am J Clin Pathol. 2015;143:645-51.

27. Shah PH, Moreira DM, Okhunov Z, Patel VR, Chopra S, Razmaria AA, et al. Positive Surgical Margins Increase Risk of Recurrence after Partial Nephrectomy for High Risk Renal Tumors. J Urol. 2016;196:327-34.

28. Borghesi M, Brunocilla E, Schiavina R, Martorana G. Positive surgical margins after nephron-sparing surgery for renal cell carcinoma: incidence, clinical impact, and management. Clin Genitourin Cancer. 2013;11:5-9.

Correspondence address: Li-qun Zhou, MD Department of Urology Inst. of Urology, Peking Univ. First Hospital, No. 8, Xishiku Street, Xicheng District Beijing, 100034, China Fax: +86 10 6655-1726 E-mail: zhouliqunmail@sina.com 